\title{
RELATO DE EXPERIÊNCIAS SOBRE A EDUCAÇÃO DE SURDOS: DA INVISIBILIDADE AO DESENVOLVIMENTO LOCAL EM TRÊS LAGOAS-MS
}

\author{
EAF EDUCATION: FROM INVISIBILITY TO LOCAL DEVELOPMENT IN TRÊS \\ LAGOAS-MS
}

\author{
Heitor Romero Marques ${ }^{1}$ \\ Adriano de Oliveira Gianotto \\ Ruthy dos Santos Barros de Oliveira
}

Doi: 10.36066/compcs.v1i23.5949

Resumo: Este artigo objetiva relatar experiências sobre a educação de surdos, traçar uma linha imagética do tempo com o intuito de analisar e apresentar os resultados sobre o processo de desenvolvimento local, no que tange ao uso da Língua Brasileira de Sinais (Libras) e a sua relação direta nos contextos de inclusão escolar e social pelos quais os surdos três-lagoenses foram ou submeteram-se no processo de ensino e aprendizagem, desde 2006 até 2018. A Lei $n^{\circ} 10.436 / 02$ e o Decreto $n^{\circ}$ 5.626/05 permeiam este recorte temporal e fundamentam esta pesquisa. Assim, exporemos que a ausência de políticas públicas locais que contemplem a comunidade surda, atribuindo-lhe, dessa forma, invisibilidade social, corroboraram na (des)construção identitária dos sujeitos surdos. Considerando os objetivos supracitados, inicialmente projetados para a realização deste trabalho, adotamos uma metodologia inerente a este formato de informação científica que é a pesquisa por meio da análise dos sujeitos surdos. Desse modo, desvendaremos o cenário invisível por eles vivenciado desde 2006, período de observações situacionais e pessoais da comunidade surda, até a posse do doutorando Adriano de Oliveira Gianotto no quadro permanente de Professor de Libras da Universidade Federal de Mato Grosso do Sul, campus de Três Lagoas, ocorrido no dia 23 de julho de 2017. Traremos à tona as inovadoras ações por ele propostas em suas palestras locais ao exigir das instituições básicas e superiores prioridade e urgência na acessibilidade linguística para que os surdos possam migrar da invisibilidade social para a auto e extra visibilidade, contribuindo de forma exorbitante para o (re) conhecimento da Libras e para o desenvolvimento local.

Palavras-Chave: Libras, educação de surdos, desenvolvimento local, visibilidade social.

Abstract: This paper aims to report experiences on the education of the deaf, to create a timeline with the objective of analyzing and presenting the results about the local development process, in the use of the Brazilian Sign Language (Libras) and their direct relationship in the contexts of school and social inclusion by which the deaf people of the city of Três Lagoas were in the process of teaching and learning, from 2006 to 2018. The Law 10,436 / 02 and Decree No. 5,626 / 05 permeate this temporal cut and base this research. Thus, we will show that the absence of local public policies that contemplate the deaf community, evidenced by the social invisibility, corroborated in the deconstruction of the deaf subjects. Considering the mentioned objectives, initially designed for the accomplishment of this paper, we adopted a methodology inherent to this format of scientific information that is the research through the analysis of the deaf individuals. In this way, we will uncover the invisible scenario they experienced since 2006, a period of situational and personal observations of the deaf community, until the investiture of the doctoral student Adriano de Oliveira Gianotto in the permanent staff of Libras Professor of the Federal University of Mato Grosso do Sul, campus of Três Lagoas, occurred on July 23, 2017. We highlight the innovative actions proposed by him in his local lectures by demanding from the basic and higher institutions priority and urgency in linguistic accessibility so that the deaf can move from social invisibility to self and extra visibility, contributing exorbitantly to the recognition of Libras and for local development.

\footnotetext{
${ }^{1}$ Doutor em Desenvolvimento Local pela Universidade Complutense de Madrid - Professor do Programa de Pós-Graduação em Desenvolvimento Local da UCDB. Av. Tamandaré 6000. Tel:. 556733123800 -heiroma@ucdb.br
} 
Keywords: Brazilian sign language (known as "Libras"), education of the deaf, local development, social visibility.

\section{INTRODUÇÃO}

Com fins informativos, este relato de experiência pretende evidenciar a "diferença" e o potencial que a informação e o conhecimento podem realizar no ambiente social por intermédio de sujeitos críticos e protagonistas que atuam socialmente em prol de uma causa, neste caso, em favorecimento e fortalecimento da comunidade surda, em especial a de Três Lagoas, em Mato Grosso do Sul. Reflete-se, em "poucas palavras", sobre a (in) existência de políticas públicas capazes de promover o (re) conhecimento, a comunicação e o desenvolvimento tanto pessoal quanto local nesta demarcação territorial.

Idealiza-se, apontar alguns exemplos de "acontecimentos históricos", em formato de projetos educacionais bem sucedidos, que proporcionaram visibilidade, conhecimento e autoconfiança à pessoa surda, bem como destacar as ações propostas por Adriano de Oliveira Gianotto desde a sua posse na UFMS ao estabelecer inúmeras ações capazes de acelerar o desenvolvimento sociocultural e local, ou seja, promover estratégias profícuas para que os surdos adquirissem conhecimento dos direitos, deveres e autonomia para abandonarem o espaço de invisibilidade social a eles destinados.

Este relato será fundamentado teoricamente no entrelaçamento de alguns conceitos, dentre eles: "visibilidade" e "invisibilidade" propostos pelo filósofo francês Maurice Merleau-Ponty e por Isabela Verri; "acontecimento linguístico", articulado por Michel Pêcheux (1983,1990); Lei $n^{\circ} 10.436 / 02$, artigo IV e faremos uma pausa linguística em 2005, ano em que o Decreto $\mathrm{n}^{\mathrm{o}}$ 5.626, contendo nove importantes capítulos, foi estabelecido, realizaremos um novo recorte, desta vez intralinguístico, e investigaremos apenas os capítulos IV e VI por estabelecerem relação conceitual com a nossa proposta de pesquisa. Estes documentos são considerados pela comunidade surda como um "divisor de águas" e, por que não dizer, um "divisor de mãos", ou seja, as mãos que usam e as mãos que não usam oficialmente a Libras. Recorreremos às experiências relatadas por Gianotto, Marques e Fernandes (2017) no livro Libras e o desenvolvimento local no contexto de territorialidades, bem como as contribuições veiculadas por Shirley Vilhalva em seu livro Despertar do silêncio, 2004. A conexão a outros conceitos emergentes no decorrer das ideias aqui inscritas comporão a base teórica desta investigação social. 
Propor sugestões que corroboram efetivamente para o Desenvolvimento Local no âmbito linguístico e no processo de inclusão escolar e social; cobrar a aplicação das propostas legais e locais aqui indicadas; atualizar as informações sobre a educação de surdos em Três Lagoas; contribuir cientificamente na esfera teórica, já que essa temática apresenta um referencial bibliográfico um tanto quanto escasso no que tange às políticas públicas que visam contemplar o "povo surdo". Almeja-se, também, ativar a "memória discursiva e social", por décadas adormecidas no seio três-lagoense, haja vista que este município possui quase 103 anos, e requerer urgência na criação e implantação de leis municipais, obedecendo aos dispositivos regulamentados nos documentos oficiais que alicerçam esta pesquisa, são algumas metas do nosso trabalho que visa, prioritariamente, tecer contribuições discursivas e práticas enriquecedoras no âmbito linguístico e social.

\section{FUNDAMENTAÇÃO TEÓRICA}

É de conhecimento da comunidade surda e de pesquisadores desta área do conhecimento de que a Língua Brasileira de Sinais tem suas raízes linguísticas arraigadas na Língua de Sinais Francesa, compartilhada no Brasil por E. Huet, o primeiro professor surdo em terras brasileiras, ela estabelece comunicação na modalidade visual-gestual, e que resistiu aos 100 anos de sua invisibilidade após a realização do Congresso de Milão. No período de 1880 até 1960, os surdos foram submetidos a viver invisíveis na sua "língua materna" ou visíveis por meio da língua oral-auditiva, desrespeitados na esfera que os mantinham vivos linguisticamente.

Intelectualmente, os pesquisadores históricos são considerados filhos biológicos do memorável grego Heródoto, reverenciado como o "pai da história", por manterem atualizado o seu genial insight: investigar os acontecimentos que permeiam os sujeitos em sociedade e registrá-los na linha do tempo vigente. São filhos biológicos por transportarem em seu ácido desoxirribonucleico (DNA) a genética que transfere ao herdeiro intelectual competências e habilidades para pensar, agir e transformar, positivamente, o mundo ao seu entorno.

Pedro Ponce de Leon (1520-1584), na Europa, foi o responsável por tornar oficial o processo de ensino e aprendizagem para surdos, porém, o método aplicado era estritamente oralista. De acordo com Gremion (1998; p. 47), apud Albres (2008), Abbé de L’Epée criou, em Paris, a primeira escola para surdos, o Instituto Nacional de Jovens Surdos de Paris 2, com uma filosofia manualista e oralista. Foi a primeira vez na história, que os surdos adquiriram o 
direito ao uso de uma língua própria. No Brasil, o Instituto Nacional de Educação de Surdos

(INES), nomenclatura atualizada, foi precursora na disseminação da Libras representado por E. Huet.

Em se tratando de filhos biológicos, Strobel (2009), conceitua o termo "povo surdo" como o "grupo de sujeitos surdos que tem costumes, história, tradições em comuns e pertencentes às mesmas peculiaridades, ou seja, constrói sua concepção de mundo através da visão", e define que a "comunidade surda" é um grupo social composto por pessoas surdas e por pessoas ouvintes que mantêm algum laço familiar ou "que participam e compartilham os mesmos interesses em comuns em um determinado local que podem ser as associação de surdos, federações de surdos, igrejas e outros".

É recorrente e sistemática a referência por uma parcela expressiva dos artigos científicos envolvendo a temática da surdez fazer menção e abordar o conteúdo da Lei $\mathrm{n}^{\mathrm{o}}$ 10.436, de 24 de abril de 2002, também o faremos. Além de reconhecer a Libras como meio legal de comunicação e expressão, é acrescentado, em seu segundo artigo, que

Deve ser garantido, por parte do poder público em geral e empresas concessionárias de serviços públicos, formas institucionalizadas de apoiar o uso e difusão da Língua Brasileira de Sinais - Libras como meio de comunicação objetiva e de utilização corrente das comunidades surdas do Brasil.

É possível inferir, então, que o Poder Legislativo Nacional executou com sucesso a sua parte para e sobre o ensino de Libras, contemplando as pessoas ouvintes, e a criação de associação de surdos, escolas bilíngues, leis e projetos sociais locais que proporcionem visibilidade e conhecimento às pessoas surdas. Felizmente, neste aspecto, há novas informações. A Secretaria Estadual de Educação (SED) de Mato Grosso do Sul disponibilizou o Curso de Libras para toda a comunidade escolar da E. E. Afonso Pena, localizada no Município de Três Lagoas, para o ano de 2018, em cujo contexto Ruth dos Santos Barros de Oliveira atuará como Tutora.

De acordo com o Decreto $\mathrm{n}^{0} 5.626 / 05$, no Artigo 22, que regulamenta a Lei $\mathrm{n}^{\mathrm{o}}$ 10.436/02, as instituições federais de ensino responsáveis pela educação básica devem garantir a inclusão de alunos surdos ou com deficiência auditiva, por meio da organização de:

I - escolas e classes de educação bilíngue, abertas a alunos surdos e ouvintes, com professores bilíngues, na educação infantil e nos anos iniciais do ensino fundamental;

II - escolas bilíngues ou escolas comuns da rede regular de ensino, abertas a 
alunos surdos e ouvintes, para os anos finais do ensino fundamental, ensino médio ou educação profissional, com docentes das diferentes áreas do conhecimento, cientes da singularidade linguística dos alunos surdos, bem como com a presença de tradutores e intérpretes de Libras - Língua Portuguesa.

$\S 1$ ํㅡo denominadas escolas ou classes de educação bilíngue aquelas em que a Libras e a modalidade escrita da Língua Portuguesa sejam línguas de instrução utilizadas no desenvolvimento de todo o processo educativo.

$\S 2$ 응 Os alunos têm o direito à escolarização em um turno diferenciado ao do atendimento educacional especializado para o desenvolvimento de complementação curricular, com utilização de equipamentos e tecnologias de informação.

$\S 3^{\circ}$ As mudanças decorrentes da implementação dos incisos I e II implicam a formalização, pelos pais e pelos próprios alunos, de sua opção ou preferência pela educação sem o uso de Libras

$\S 4^{\circ} \mathrm{O}$ disposto no $\S 2^{\circ}$ deste artigo deve ser garantido

Destacamos que o Poder Judiciário, que tem a função de julgar como procedente ou não as leis criadas pelo legislativo, também executou com maestria o seu papel. Por outro lado, o Poder Executivo, responsável por administrar o país, realizar políticas públicas que sejam de interesse da população e aplicar leis, não desenvolveu em grandes proporções a sua função. Compreendemos como "apoiar o uso e difusão da Libras", a elaboração e aplicação de Cursos Profissionalizantes, Seminários, Palestras e Formação Continuada.

A inexistência de escola bilíngue, "aquelas em que a Libras e a modalidade escrita da Língua Portuguesa sejam línguas de instrução utilizadas no desenvolvimento de todo o processo educativo", desde as séries iniciais ocasionou atraso linguístico tanto em Libras quanto em Língua Portuguesa. Isso se refletiu tanto na insegurança linguística apresentada pelos estudantes surdos quanto no uso da LP/L2 pelos estudantes ouvintes na tentativa de uso da Libras/L2 para manter a comunicação com os surdos. $\mathrm{O}$ insucesso inclusivo reside no fato da comunidade escolar não ter recebido formação antecipada para inserir os surdos no ensino regular, como relatam diversos artigos relacionados a esta temática. Se assim houvesse sucedido, vários problemas, principalmente no âmbito da comunicação e do relacionamento (des) humano, seriam suprimidos. Acreditamos ser este o maior erro cometido pelos governantes: não capacitar a comunidade escolar antes de inseri-los neste espaço educacional, aumentando, desse modo, o índice de bullying, depressão, desinteresse e evasão escolar.

Sobre "a presença do tradutor-intérprete de Libras" (TILS) nas unidades escolares, foi, sim, uma inovação pontual estipulada pelo Decreto em epígrafe. Mas faltaram, neste documento, o esclarecimento e a distribuição das atribuições no exercício da profissão de 
TILS. Tal regulamentação só foi sancionada pela Lei $\mathrm{n}^{\mathrm{o}} 12.319$, no dia $1^{\circ}$ de setembro de 2010. O atraso desta legalização sobrecarregou os atuantes nesta profissão, pois a falta de esclarecimento legal em tempo hábil associados à desinformação dos professores sobre a educação de surdos fez com que todas as atribuições dos docentes para com o surdo fossem automaticamente delegadas em caráter de exclusividade aos TILS, como acontece na maioria das instituições em que esses profissionais atuam.

Essa superinteressante viagem histórica e coletiva está sendo realizada porque almejamos, dentre outros intentos, construir discursivamente o perfil histórico da educação de surdos, bem como tomar ciência formal das influências internas e externas que corroboraram no processo de construção indenitária deste grupo social, além de participar das ações que contribuirão com o Desenvolvimento Local, essencialmente, no aspecto linguístico, no sentido de disseminar o conhecimento e o uso da Libras nos diversos ambientes sociais.

Diante disso, refletiremos na sequência, sobre o conceito de "invisibilidade" na voz de Isabela Verri (2009, online):

O termo invisibilidade social é um conceito que foi criado para designar as pessoas que ficam invisíveis socialmente, seja por preconceito ou indiferença. Esse conceito é bastante amplo, abarcando os vários fatores que levam a uma invisibilidade, tais como sociais, estéticos, econômicos, históricos, culturais, etc. [...] sempre ocorre em um contexto onde haja relações hierarquizadas, mesmo que irrefletido, e atingindo exclusivamente aqueles que estão à margem da sociedade.

Ser invisível, então, grosso modo, é viver nas sobras, dependente, camuflado, subordinado, inferiorizado, coadjuvante, não ser notada a presença, etc.. São exatamente essas as características atribuídas aos surdos três-lagoenses no que concerne à sua singularidade linguística. Para isso, os projetos mencionados abaixo foram criados e aplicados visando, mesmo que em âmbito escolar, amenizar o excesso de invisibilidade linguística e social, pois nestas circunstâncias trazer à tona discursos sobre cultura, identidade, língua e visibilidade soa como utopia. Trabalhar esses conceitos nestas distorcidas condições exige do profissional conhecimento, estratégia, metodologia, sagacidade e protagonismo nas práticas educativas para impedir que a história, a identidade, a cultura e a própria língua façam sentido em sua perspectiva de vida pessoal e social.

Seguindo essa linha discursiva, convidamos o filósofo francês Maurice Merleau-Ponty (2009, p. 224) para estabelecer a relação visibilidade versus invisibilidade:

Quando digo que todo visível e invisível, que a percepção é impercepção, que a consciência tem um 'punctum caecum', que ver é sempre ver mais do 
que se vê. É preciso não compreender isso no sentido da contradição: é preciso não imaginar que junto ao visível, perfeitamente definido como em-Si um não visível (que seria apenas ausência objetiva, isto é, presença objetiva alhures, num alhures em si). É preciso compreender que é a visibilidade mesma quem comporta uma não visibilidade.

Elaboramos uma rápida pesquisa sobre a expressão "punctum caecum" e descobrimos que se refere ao "ponto cego da retina". O complexo foi assimilar a ideia conceitual de que "todo visível é invisível". Concluímos, por meio de uma comparação metafórica, que a retina é formada pela sociedade civil, detentora do poder e de visibilidade exacerbada, e que o "ponto cego" é o lugar, ou seja, o não-lugar ocupado pelas classes minoritárias, que sobrevivem dos "atos falhos" por vezes ocorrentes, estabelecendo, dessa forma uma linha tênue entre o "sim" e o "não", entre o "ver" e o "desver", entre "incluir" e "segregar", entre "visibilizar" e "invisibilizar". Decorre disso a nossa função social: criar estratégias para que a igualdade e a visibilidade seja um direito de todos.

$\mathrm{O}$ direito à igualdade e à visibilidade foram conquistados por vários surdos brasileiros. Em nosso estado, Shirley Vilhalva e Adriano Oliveira Gianotto são referências, principalmente quando o assunto é a quebra de paradigmas, a resistência ao sistema educacional e social exclusivos, ao "empoderamento surdo", ao bilinguismo. Enfim, em todas as temáticas que destacam os sujeitos que adquiriram respeito e valorização linguística. Vilhalva (2004, p.37-8) expôs em seu livro o sentimento adquirido ao se auto reconhecer na Libras e confirmou que:

Através da Língua de Sinais, que é uma Língua completa, com estrutura independente da Língua Portuguesa Oral ou Escrita possibilitando o desenvolvimento cognitivo do indivíduo surdo, favorecendo o seu acesso a conceitos e conhecimentos que se fazem necessários para sua interação com o outro e o meio em que vive, percebi que minhas dúvidas diminuíram e o meu prazer de viver com os ouvintes aumentou de forma viva na comunicação.

A vasta experiência sobre os temas: visibilidade e Desenvolvimento Local conferiram a Gianotto, Marques e Fernandes (2017, p.87) a autoridade para firmar que

Os movimentos dos excluídos se articularam de forma a produzirem novas maneiras de pensar e criar sua visibilidade mesmo em meio ao poder hegemônico. A partir desse esforço de mudança, começou a ideia do desenvolvimento local. Surgiu uma discussão mais forte ao redor das potencialidades de lugares antes apenas conhecidos como subdesenvolvidos.

Ausência de escolas bilíngues, associação de surdos, central de TILS, lei municipal são "acontecimentos" que aprisionam o surdo na invisibilidade. Três Lagoas, podemos dizer, 
está se esforçando para desconhecer esses "lugares subdesenvolvidos" nas questões socioculturais e linguísticas e, desse modo, desaparecer do "ponto cego" social, e consequentemente se fazer presente na "retina" social por meio de ações conjuntas capazes de alçar como referência de acessibilidade linguística e desenvolvida intelectualmente em diferentes áreas do conhecimento.

De acordo com Pêcheux (1983-1990, p.17) "O acontecimento é o ponto de encontro entre uma atualidade e uma memória". O acontecimento histórico é apreendido na formulação dos enunciados que se entrecruzam e dão consistência ao dizer. A historicidade se faz notar no discurso pelo trabalho da memória que irrompe na atualidade. Assim, produzimos um acontecimento discursivo ao eclodirmos memória e atualidade, impedindo que toda essa trajetória histórica residisse apenas no mundo das ideias, mas que seja impetuoso e perpetuado no mundo dos acontecimentos.

\section{RELATO DE EXPERIÊNCIA}

A História da educação dos surdos três-lagoenses é o tema central a ser aqui discutido, por meio de um relato de experiência, enfatizando, essencialmente, o período de 2006 a 2018. Foi em 2016 que Ruth dos Santos Barros de Oliveira ingressou no meu primeiro curso de Libras, com duração de dois anos, na cidade de Araçatuba, interior de São Paulo. A memória afetiva não permitiu que o primeiro contato com uma surda residisse apenas em vastas lembranças. Quando criança, na cidade de Anastácio, também no Estado de Mato Grosso do Sul, uma amiga surda, e se não falha a memória, cujo nome era Clara. Atualmente, Ruth dos Santos Barros de Oliveira tem ciência de que aquele "mover de mãos" associado às expressões faciais e/ou corporais era a tão resistente Língua Brasileira de Sinais. “Comunicávamos e brincávamos com os patins rosa que ela sempre trazia pelo olhar, ela nos ensinou a utilizá-los. "C-A-S-A", foi o primeiro sinal que aprendemos, talvez por ser o sinal mais icônico para sabermos a direção de sua casa, em meados de 1995". Ruth dos Santos Barros de Oliveira continua em seu relato afirmando que

[...] foi Clara que nos fez perceber que existiam outras formas de comunicação além da oral-auditiva, que àquela língua que se auto identifica na modalidade visuo-espacial possui todas as características e estruturas linguísticas para classificá-la como uma língua viva que passa por constantes atualizações, como todas as línguas naturais. 
Devido ao espaço limitado, neste artigo, para expor mais experiências com Libras e almejar focar o período da educação de surdos em Três lagoas, faremos um salto temporal para o ano de 2006, para continuarmos com o relato, nos seguintes termos:

De 2006 a 2008 adquirimos no Curso de Libras, em Araçatuba, conhecimento básico e intermediário sobre a língua em questão, no entanto, nos faltava o contato direto com surdos para desenvolver fluência na comunicação. Debruçamos nos estudos e obtivemos aprovação como Tradutora Intérprete de Língua Brasileira de Sinais (TILS) pelo Centro de Formação de Profissionais da Educação e de Atendimento às Pessoas com Surdez (CAS), em 2011, podendo atuar até o $9^{\circ}$ ano do ensino fundamental, e no dia 8 de dezembro de 2014 passamos por nova avaliação e aprovação pelo CAS para atuar como TILS também no ensino médio.

Seguindo a máxima de que a cultura é gestada e formada no seio social mediante as constantes relações interpessoais, também o universo da Libras é construído no cotidiano das pessoas. Assim, Ruth dos Santos Barros de Oliveira segue em seu relato afirmando que no dia 28 de janeiro de 2011 fora aprovada na avaliação realizada pelo CAS, dia inesquecível em sua vida, quando iniciou o segundo contato direto com pessoas surdas, já na condição de profissional de TILS. Em março do mesmo ano atuou com junto a um aluno do sexo masculino (G.C) e uma estudante do sexo feminino (V.C), ambos matriculados na sétima série, turma D ( $\left.7^{\circ} \mathrm{D}\right)$ no período vespertino na Escola Estadual Afonso Pena. Admite que, na primeira semana de trabalho, não identificou nenhum problema, pois vivia um momento "mágico" diante do objetivo de atuação como TILS. Na semana seguinte, já mantendo o controle das emoções, percebeu que havia alguns discursos desconexos naquele ambiente escolar. Ainda que desconhecendo a Lei $n^{\circ} 10.436 / 02$ e o Decreto 5.626/05 notou que muitas metodologias pedagógicas deveriam ser remodeladas, no sentido de buscar outro modelo de educação para surdos.

Em vista do exposto em seu relato, Ruth dos Santos Barros de Oliveira sentiu-se motivada em contribuir de alguma forma e por isso, daquele momento em diante sentiu-se na responsabilidade de desenvolver projetos que visassem incluir os surdos naquele espaço escolar, mediante a potencialização de ações para que o estudante surdo fosse evidenciado como um sujeito ativo, em defesa de sua língua para que fosse respeitada em todos os espaços escolares e sociais. Foi na realização dos projetos citados a seguir que a mesma pode dizer de forma clara e objetiva para a comunidade escolar e, principalmente, para os surdos que a educação bilíngue não é um projeto utópico, mas perfeitamente factível, quando cada um faz 
a sua parte.

O primeiro projeto realizado com a participação de toda a comunidade escolar, foi a edição de um vídeo em Libras $^{2}$ em que todos os profissionais atuantes naquela unidade participaram. Foi um dos primeiros momentos de visibilidade social da comunidade surda porque este evento foi veiculado pelo jornal local "Concórdia Notícias"3 Este vídeo é considerado um dos momentos históricos registrados em comemoração ao "Dia do Surdo", em 26 de setembro de 2013. Devido ao sucesso deste primeiro projeto visando a acessibilidade linguística, muitos profissionais e/ou estudantes demonstraram interesse em aprender Libras. Naquele ano, Ruth dos Santos Barros de Oliveira considerou ser aquele o momento ideal para inserir o ensino de Libras para toda a comunidade escolar.

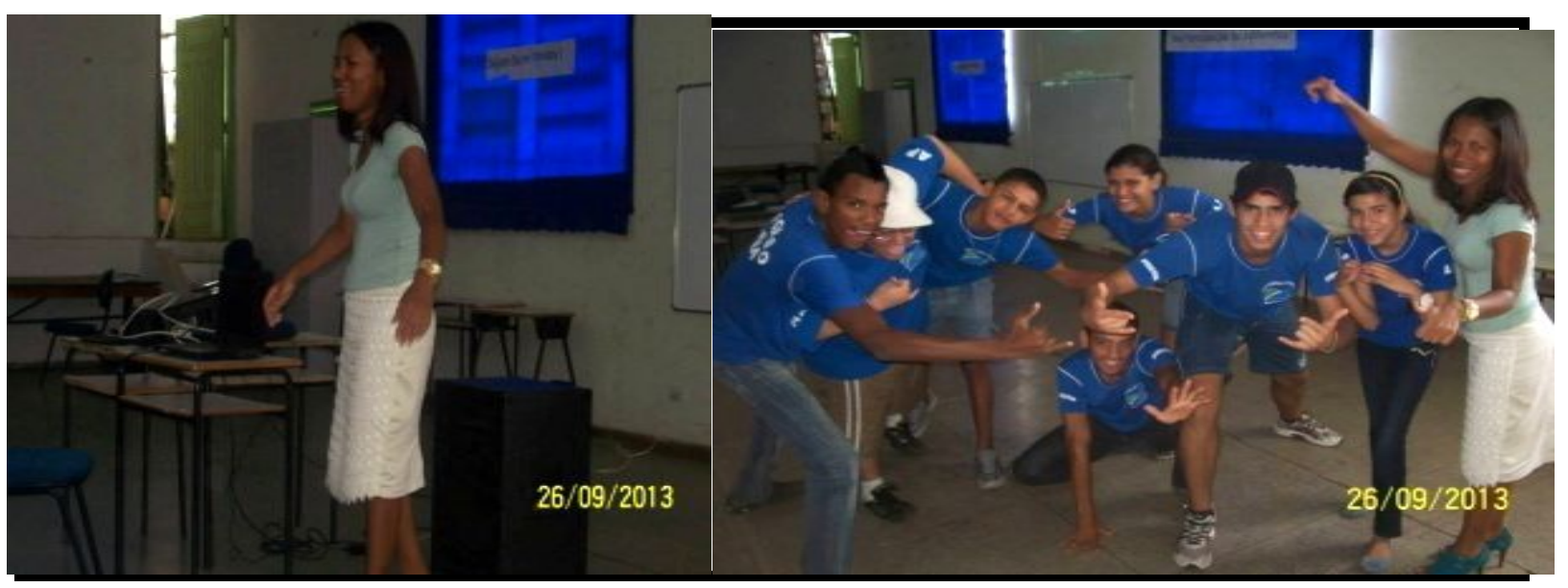

Figura no 1 - Culminância do projeto "Fale com as minhas mãos", 2013. Fonte: Acervo de Ruth dos Santos Barros de Oliveira.

O referido projeto deu-se mediante redação e apresentação à direção escolar, que o aprovou sob o título "Fale com as minhas mãos" e em 2014, passou a consistir no ensino com sinais em Libras diariamente. Alguns TILS incentivaram e participaram da disseminação deste projeto social. Cada dia, durante o recreio na sala dos professores, um TILS ensinava um sinal para os docentes. Estes, por sua vez, deveriam repassar o conhecimento adquirido

\footnotetext{
${ }^{2}$ https://www.youtube.com/watch?v=0alte03vgso

${ }^{3}$ https://www.youtube.com/watch?v=tYnUPcms2iM Compocs, v1, n 23 - jul -dez 2020
} 
aos estudantes na quarta ou quinta aula, já que uma ínfima quantidade de professores não aceitaram participar desta ação. Ruth dos Santos Barros de Oliveira afirma textualmente que:

Recordo-me que na primeira semana de realização deste trabalho os estudantes surdos vieram extremamente felizes, me agradecer porque muitas pessoas da escola estavam cumprimentando-os, iniciando os primeiros contatos com eles, queriam saber o que eu fiz para que muitos começassem a visualizá-los, a notar a existência deles ali.

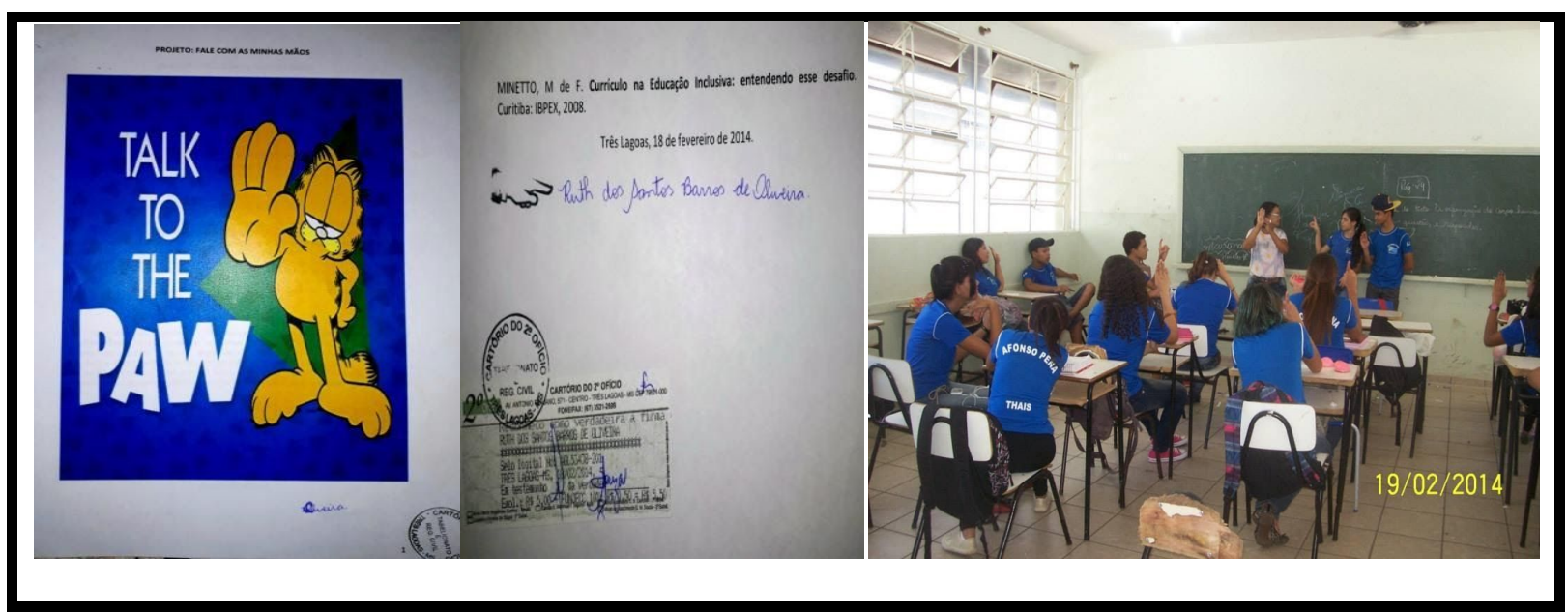

Figura n⿳0 2 - Aplicação do Projeto "Fale com as minhas mãos", 2014.

Fonte: Acervo de Ruth dos Santos Barros de Oliveira

Ruth dos Santos Barros de Oliveira conta que a terceira etapa de acontecimentos, neste mesmo ano, foi a "Noite de autógrafos" realizada no dia 26 de setembro como forma de comemorarmos e reforçarmos a importância e a História embutidas nesta data comemorativa. Os estudantes surdos que frequentavam a Sala de Recursos Multifuncionais (SRMF's), atualmente denominadas de Atendimento Educacional Especializado (AEE), foram orientados para que junto com o relatório de vida, seus pais e/ou responsáveis pudessem contar pessoalmente como foi que tudo aconteceu, desde a descoberta de que seu/sua filho (a) era surdo(a). Para tanto foi criado um livro contendo a biografia dos estudantes, intitulado Escrevendo Nossa História e divulgado para a comunidade escolar naquela mesma noite. $\mathrm{O}$ evento foi profundamente marcante para todos: pais, filhos, TILS e comunidade escolar. Desse dia em diante os estudantes surdos tornaram-se ainda mais visíveis e presentes na E. E. Afonso Pena, agora com mais propriedade sobre a história da vida deles mesmos. Estes projetos lhes transferiram maturidade, autoconhecimento, autoaceitação, conhecimento da História da Educação de Surdos em âmbito mundial, pois a palestrante Maria Inês, ex-técnica do Núcleo de Educação Especial (NUESP) aceitou discorrer sobre a trajetória histórica dos 
surdos, como vemos nas imagens abaixo.

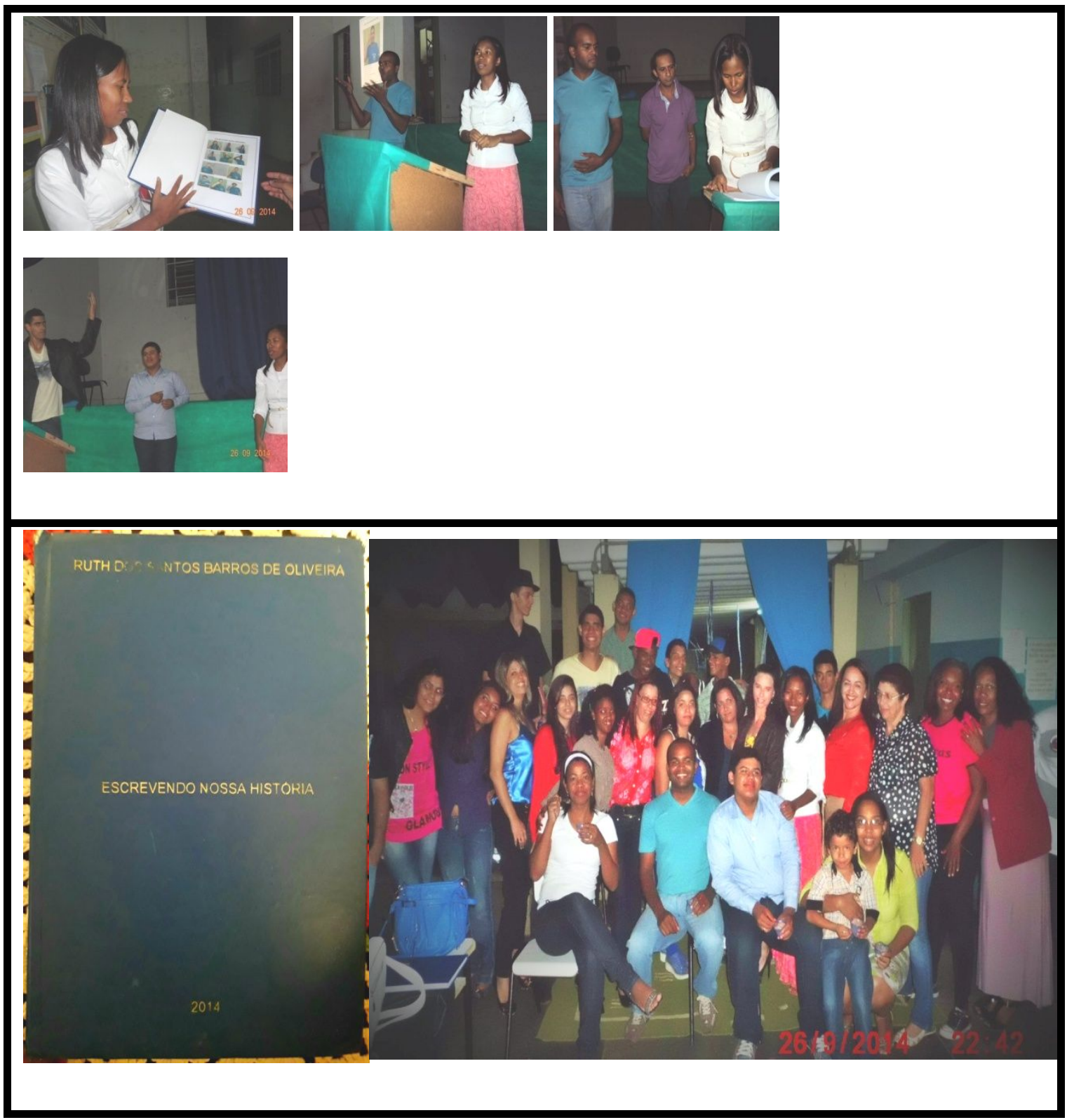

Figura no 3 - Palestra em comemoração ao "Dia do Surdo/Noite de autógrafos", 2014.

Fonte: Acervo de Ruth dos Santos Barros de Oliveira.

Ruth dos Santos Barros de Oliveira relata ainda que atuou como professora de Língua Portuguesa (LP) como segunda língua (L2) para surdos de 2013 a 2015, e que só parou de atuar nesse âmbito educacional porque tomou posse no Quadro Permanente de Professores na Rede Estadual no cargo de Professora de Língua Portuguesa como primeira língua (L1) para ouvintes. Conta que foi na SRMF's que desenvolvera inúmeros projetos que visavam o ensino da LP, na modalidade escrita, objetivando que o estudante surdo adquirisse habilidades e competências linguísticas. Recorda que tal objetivo não obteve êxito satisfatório devido à idade cronológica dos mesmos e ao fatídico atraso linguístico ocasionado por diversos fatores 
e que houve a realização de vários outros projetos que viabilizaram a aquisição do conhecimento relacionado a temáticas escolares, assim como proposta de projetos que priorizavam temáticas socioculturais, dentre eles: 1) "Dicionário Manual" que tinha como foco pesquisar, recortar e colar inúmeras imagens em um papel mais resistente (caixa de papelão), no verso da imagem foi inserido a nome da cada imagem e o seu sinal em Libras correspondente, ao final somavam quase 800 imagens/palavras/sinais. No projeto 2) "Meu Brasil", foi criado o mapa do Brasil em Libras, cada estado recebeu a imagem da sua bandeira e o sinal respectivo. Neste projeto também houve a projeção de filmes que retratavam e mostravam as características geográficas e culturais de cada lugar. Já o projeto 3) intitulado “100 Lagoas", pretendeu comemorar no dia 15 de junho de 2015 o centenário de Três Lagoas, no qual visitamos os principais lugares históricos da cidade para conhecê-los e pesquisarmos sobre a relevância daquele ponto turístico na construção e Desenvolvimento Local de Três Lagoas, como vemos nas imagens abaixo.

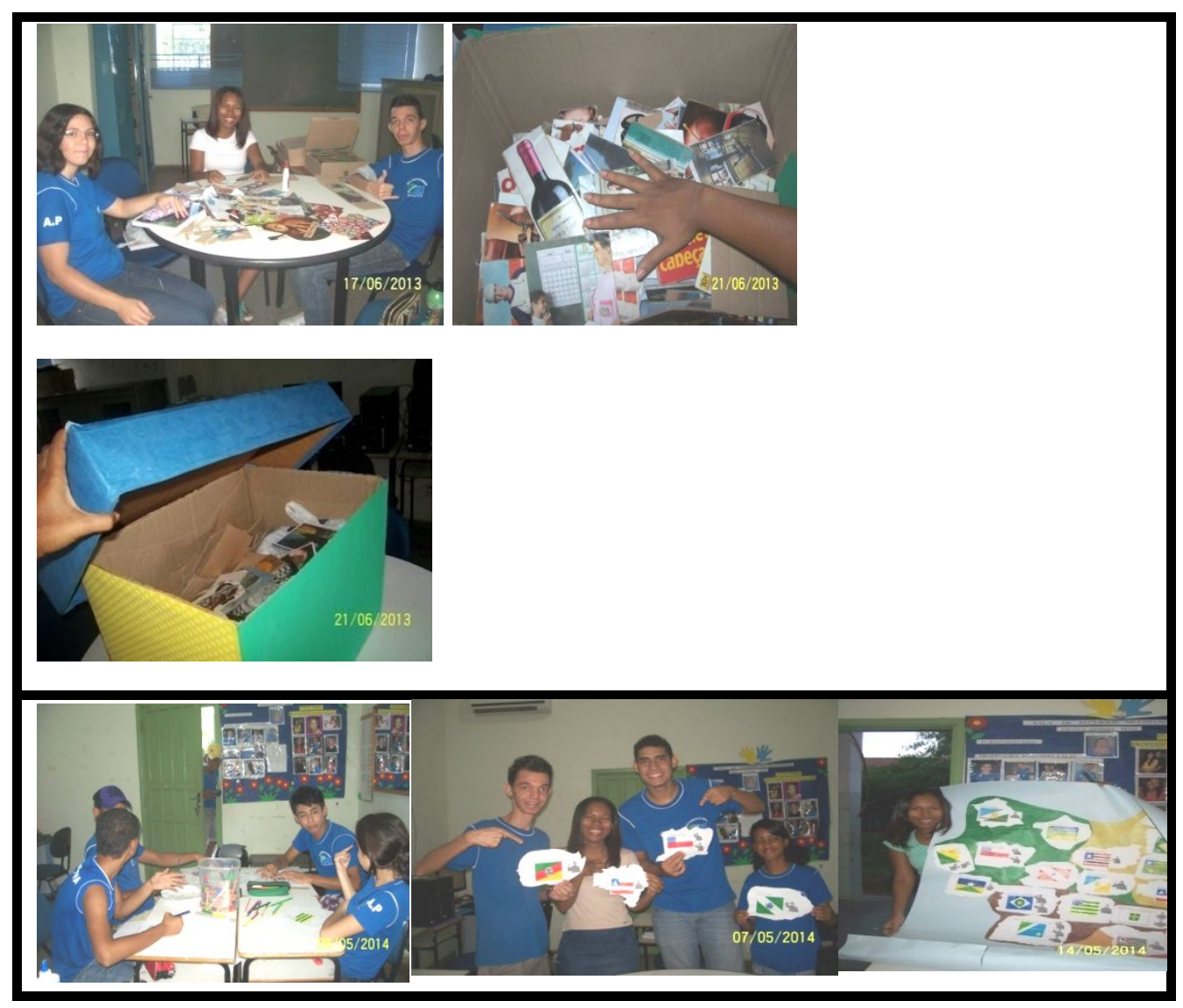




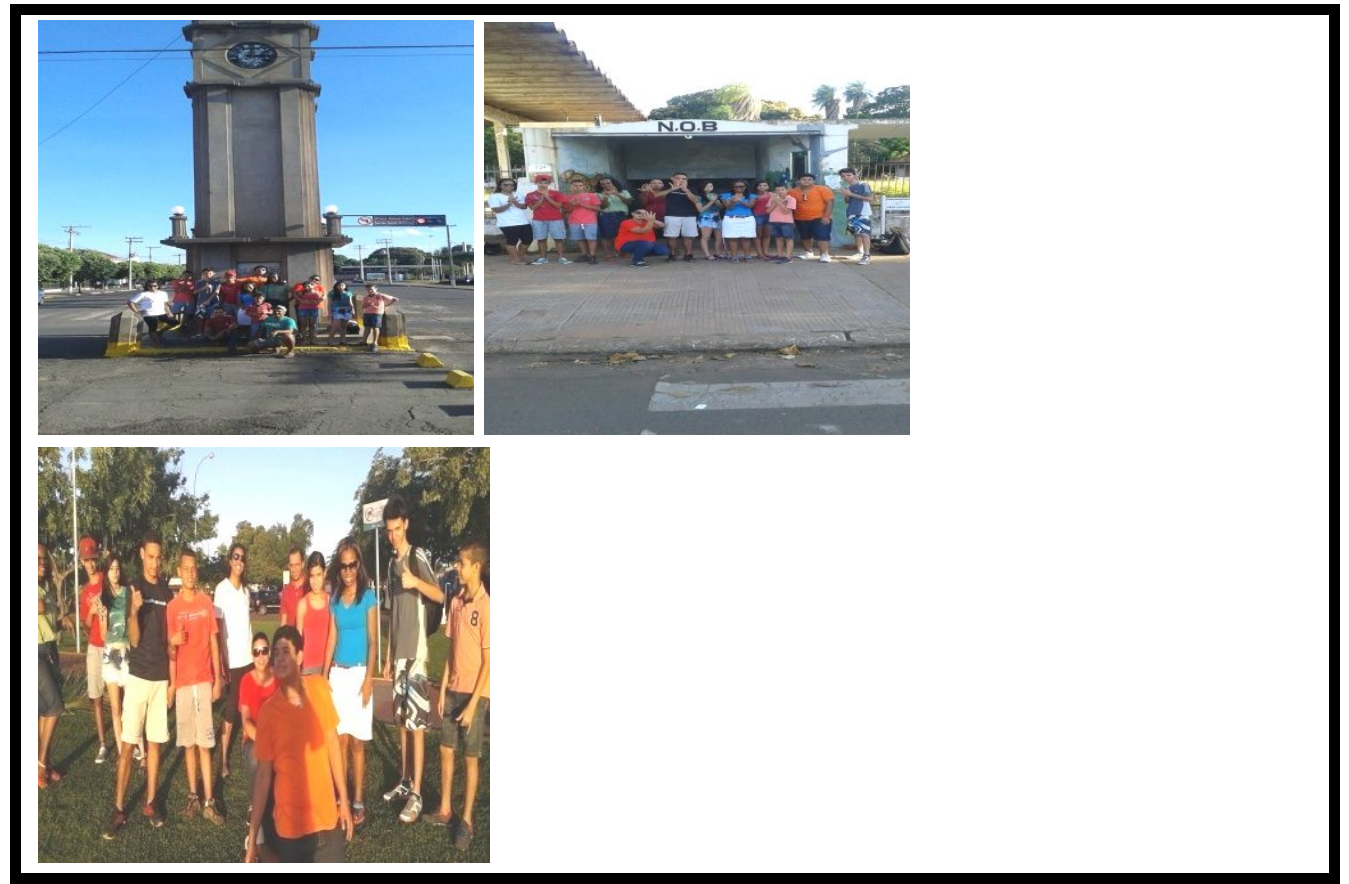

Figura n 4 - Projetos: "Dicionário Manual", 2013; "Meu País", 2015; "Cem Lagoas", 2015. Fonte: Acervo de Ruth dos Santos Barros de Oliveira.

Oliveira ainda enfatiza que durante anos da sua vida dedicou excessivas horas de trabalho, pois a causa exigia aceleramento no processo de ensino e aprendizagem, haja vista o atraso linguístico, a invisibilidade escolar, social e o, até então, desconhecido tema sobre "desenvolvimento local em contexto de territorialidades" com possibilidade de conhecimento pela leitura da obra disseminada por Adriano de Oliveira Gianotto. Esses e outros projetos informais tinham em sua base conceitual o compartilhamento de conhecimento formal, informal, educacional, socioculturais e relacionados ao autoconhecimento no sentido de que, ao final deste processo de ampliação do saber, os surdos participantes fossem capazes de reconhecerem-se como detentores de uma língua que atribui aos sujeitos o empoderamento necessário para conviver e agir socialmente. Nesses três anos de contribuições na área da educação de surdos e do provimento de estratégias e metodologias capazes de transferir os saberes, percebemos que nada supria a necessidade de ter um representante surdo, ativo e protagonista em suas ações sociais.

Ainda em seu relato, Ruth Oliveira afirma que era fundamental que existisse uma liderança surda com consciência política e social para assumir este posto e conduzir o movimento surdo em Três Lagoas, cujo trabalho foi executado desconsiderando as situações adversas, mais especificamente nas questões linguísticas da Libras e sua relação direta com a Língua Portuguesa em todas as suas nuances e conflitos. Na ocasião houve a disseminação da informação sobre a existência do CAS e a relevância de que a frequência nos cursos poderia 
ampliar-lhes, de forma imensurável, o conhecimento formal e informal. Igualmente foi ampliado o vocabulário sinalizado e escrito em L2; e norteado quanto às questões físicas, psicológicas e pessoais. Enfim, cada dia que passava era crucial a presença de um representante surdo.

Finalizada esta trajetória no intuito de contribuir com ações que promovessem a inclusão, o conhecimento, a visibilidade e o desenvolvimento intralocal, ainda não foi possível selecionar e organizar as palavras para expressar o sentimento, a alegria e o alívio, diante das situações já explanadas no decorrer deste relato, ao receber a notícia de que Adriano de Oliveira Gianotto era o "sujeito" que havia passado em $1^{\circ}$ colocação no concurso para pertencer ao quadro permanente de professores da UFMS/CPTL. Vale destacar que este foi mais um "acontecimento linguístico" e sociocultural que impactou positivamente a comunidade surda três-lagoense. Adriano de Oliveira Gianotto é o único surdo nesta cidade que possui graduação, isso já seria o bastante, no entanto, além disso, ele é Pós-graduado, Mestre e é o único surdo Doutorando no Estado de Mato Grosso do Sul.

Era de um representante desta estirpe que a comunidade surda três-lagoense necessitava para tê-lo como líder, função esta que ele desempenhava em Campo Grande. Desde a sua chegada em Três Lagoas, ele foi consagrado como líder, assumindo assim, algumas responsabilidades como a de apregoar e lutar pelo reconhecimento da Libras e de tantas outras propostas de intervenção social. Sobre tudo isso, no dia 23 de julho de 2017, Adriano de Oliveira Gianotto foi empossado em Três Lagoas, desde então vem propondo e cobrando das autoridades, ações para que os surdos sejam contemplados, assistidos, valorizados e linguisticamente respeitados. Em menos de um ano já desenvolveu diversas ações neste sentido, alguns a sociedade em geral teve conhecimento por meio de notícias veiculadas nos jornais locais, outros, só a comunidade surda teve conhecimento e participação. Seu primeiro projeto foi promover um seminário, aberto ao público em geral, no qual registrou sua experiência e trajetória de vida que iniciou na invisibilidade, transpassou a visibilidade social e se perpetuou no Desenvolvimento Local. Ruth Oliveira afirma que teve a honra de ser uma das TILS convidadas para interpretar o seminário intitulado Empoderamento do surdo para uma educação bilíngue.

Outro evento foi inserido no rol de ações que potencializaram a visibilidade do sujeito surdo e de todas as características que lhe são inerentes. No dia 26 de outubro de 2017, em Compocs, v1, n 23 - jul -dez 2020 
Campo Grande, foi realizado pela Universidade Católica Dom Bosco (UCDB) em 2017 o lançamento do livro publicado por Adriano de Oliveira Gianotto, Heitor Romero Marques e Priscila Keila de Mendonça Fernandes intitulado Libras e o desenvolvimento local em contextos de territorialidades. É de suma importância estabelecer a relação entre a publicação deste livro e a proposta de redação do Exame Nacional do Ensino Médio (ENEM), que exigiu a produção de um texto dissertativo-argumentativo sobre o tema Desafios para a formação educacional de surdos no Brasil, causando polêmicas e discussões sobre esta temática em todo o território brasileiro, "acontecimento" este nunca presenciado em âmbito nacional.

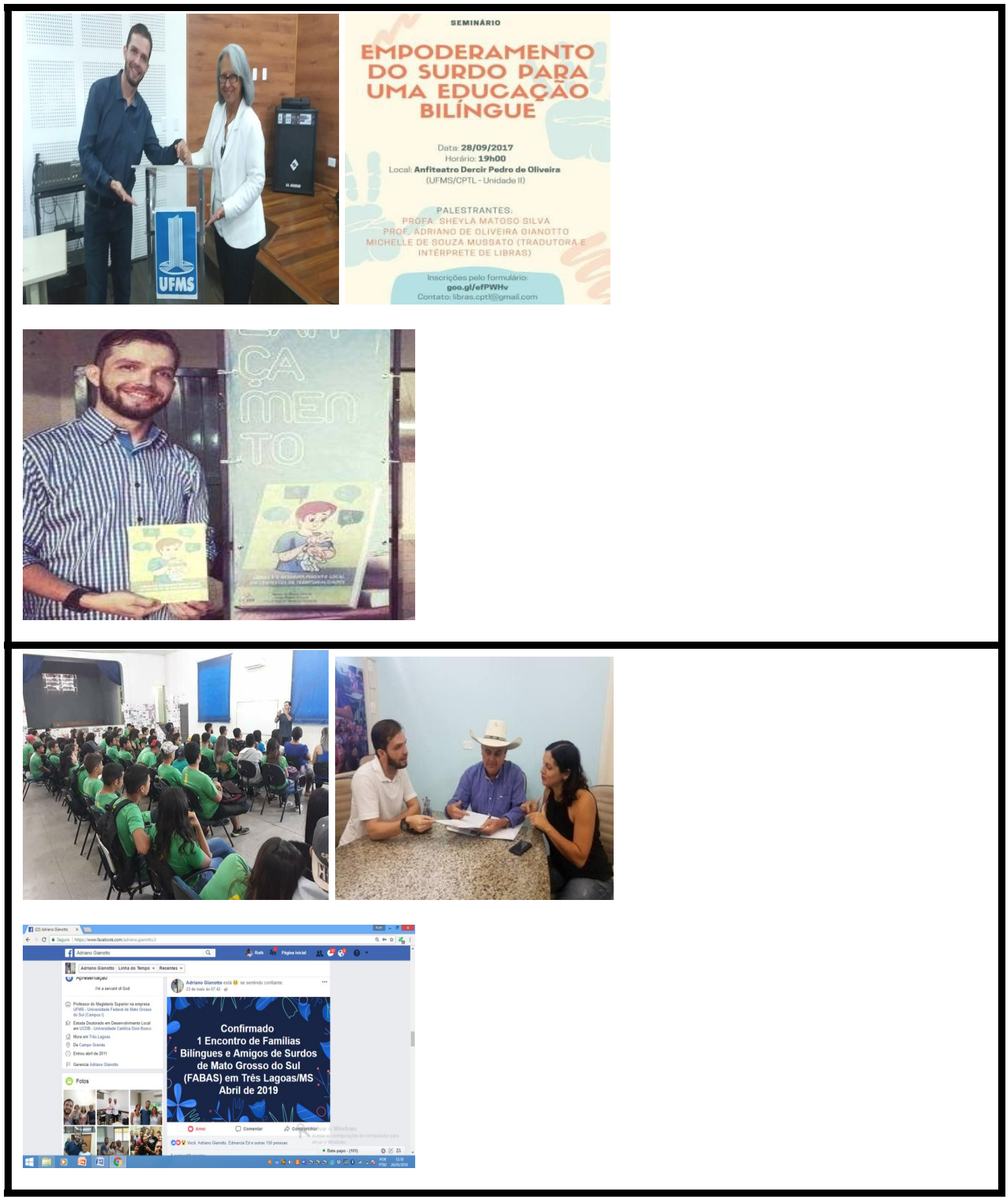


Figura $\mathrm{n}^{\circ} 5$ - Trajetória e ações desenvolvidas Gianotto desde a posse no concurso em 2017, visando a visibilidade social, empoderamento do movimento surdo e acessibilidade linguística em Três Lagoas. Fonte: Facebook de Adriano de Oliveira Gianotto e acervo de Ruth dos Santos Barros de Oliveira.

No dia 24 de abril de 2018, Adriano de Oliveira Gianotto foi convidado pela TILS Edmárcia Santos Pereira para dissertar sobre a importância desta data na E. E. Afonso Pena. O resultado da palestra foi a conscientização e esclarecimento de vários tópicos sobre a educação de surdos no Brasil. Os estudantes do ensino fundamental, $9^{\circ}$ anos e do ensino médio $\left(1^{\circ}, 2^{\circ}\right.$ e $\left.3^{\circ}\right)$ foram convidados para ampliarem os seus conhecimentos sobre a Lei $n^{o}$ 10.436/02, que neste dia comemorava 16 anos de oficialização, além de apanhados gerais sobre o Decreto $\mathrm{n}^{\mathrm{0}} 5.626 / 06$.

Sob a orientação de Ruth Oliveira, os estudantes do $9^{\circ} \mathrm{C}$, dos quais é professora de Língua Portuguesa, produziram, em formato de vídeo, utilizando movie maker, interessantes relatórios sobre o que aprenderam naquele momento de aprendizagem. Tais relatórios foram postados no Facebook próprio desta turma 4 .

Excedendo toda e qualquer expectativa, no dia 26 de abril deste mesmo ano, Adriano de Oliveira Gianotto e representante da comunidade surda três-lagoense, acompanhado da TILS Sheyla Matoso Silva, também professora na UFMS, apresentou ao Prefeito Ângelo Guerreiro propostas para que a Libras adquira status de Lei Municipal. Na oportunidade aquela autoridade deixou claro, que apoia esta causa com pretensões inclusivas e que está disposto a somar forças e "trabalhar em prol da criação dessa Lei e que tem certeza que ajudará as famílias e toda a população três-lagoense, colocando-se à disposição para estudar junto ao Jurídico a viabilidade da criação desse projeto. Este "acontecimento social" foi veiculado por dois jornais locais ${ }^{5}$. É perceptível que Adriano de Oliveira Gianotto batalha incansavelmente para que o surdo tenha condições de ser protagonista social. Além da luta pelo Desenvolvimento Local, o mesmo divulgou suas experiências em várias cidades do país neste mesmo espaço temporal, provando que o cargo ao que fora nomeado está muito bem representado.

\footnotetext{
${ }^{4}$ https://www.facebook.com/groups/874328966081742/

http://www.treslagoas.ms.gov.br/noticia/professor-da-ufms-solicita-ao-prefeito-de-tres-lagoas-criacao-de-leimunicipal-de-libras/14469/

http://www.perfilnews.com.br/noticias/bolsao/professor-da-ufms-solicita-ao-prefeito-de-tres-lagoas-criacao-d e-lei-municipal-de-libras

Compocs, v1, n 23 - jul -dez 2020
} 
Em seu admirável empenho pela visibilidade e empoderamento do surdo, deu-se no mês junho, mês do respeito à inclusão, na UFMS, um relato de experiência de sua vida sobre o tema Inclusão e exclusão: da invisibilidade para a visibilidade.

\section{CONCLUSÃO}

Após a apresentação dos "acontecimentos linguísticos" que antecederam o dia 23 de julho de 2017 e os "acontecimentos sociais" que sucederam esta data, analisamos ações pontuais sobre a história da educação de surdos em Três Lagoas. Refletimos que anteriormente, por mais que inúmeros projetos tenham sido efetivamente desenvolvidos, os surdos viviam "camuflados" socialmente, sem autonomia para expor sua língua, para exigir respeito, em síntese, com poucas estratégias de autodefesa.

Ter o contato direto com Adriano de Oliveira Gianotto que tem 36 anos de idade, sendo, portanto, o surdo "mais velho" atuante socialmente, foi para o povo surdo um momento de impacto indenitário, pois identificaram nele a comprovação de que a surdez não é empecilho para a realização de sonhos. Infelizmente, a ideologia ouvintista repercutiu em atraso linguístico e, em alguns casos, identitário, mas este relacionamento sociocultural trouxe visibilidade e autorreflexão na comunidade surda. Já é possível notar modificações no Desenvolvimento Local, desenvolvimento este que teve início na concepção que a sociedade tinha sobre os surdos; ideias foram discutidas e ações foram propostas.

Finalmente, a Lei e o Decreto supracitados começaram a fazer sentido linguístico e a surtir efeito social em Três Lagoas. Foi disseminada a informação de que podemos ter esperança em um futuro, melhor dizendo, em um presente inclusivo com práticas sociais que contemplem os surdos em sua peculiaridade linguística. Acreditamos que as futuras gerações de surdos três-lagoenses terão a sua língua materna valorizada desde a detecção nos recém-nascidos. Cremos também que a geração presente terá muitas histórias para registrar sobre o Desenvolvimento Local e o reconhecimento da Libras por meio da promulgação de lei municipal e das demais ações que tornarão os surdos empoderados e conscientes de seu papel social.

Finalizamos este artigo na certeza de que deixamos a nossa contribuição discursiva, cultural, linguística e social refletindo sobre os discursos que "estão ainda por dizer", deixando a nossa marca nas contribuições relacionadas à visibilidade e ao Desenvolvimento 
local em Três Lagoas, Estado de Mato Grosso do Sul.

\section{REFERENCIAS}

ALBRES, Neiva de Aquino. História da Língua Brasileira de Sinais em Campo Grande MS. Petrópolis: Arara Azul, 2005.

BRASIL. Lei $\mathrm{n}^{\mathrm{o}}$ 10.436, de 24 de abril de 2002. Dispõe sobre a Língua Brasileira de Sinais Libras e dá outras providências. Diário Oficial da União, Brasília, DF, 25 abr. 2002.

BRASIL. Decreto $\mathrm{n}^{0}$ 5.626, de 22 de dezembro de 2005. Regulamenta a Lei no 10.436, de 24 de abril de 2002, que dispõe sobre a Língua Brasileira de Sinais - Libras, e o art. 18 da Lei no 10.098 , de 19 de dezembro de 2000.

CHARAUDEAU, Patrick \& MAINGUENEAUS, Dominique. Dicionário de análise do discurso. São Paulo: Contexto, 2004.

FOUCAUlT, Michel. A ordem do discurso. Trad. de Laura F. A. Sampaio. São Paulo: Edições Loyola, 1996, [1971].

GIANOTTO, Adriano de Oliveira. MARQUES, Heitor Romero, FERNANDES, Priscila Keila de Mendonça. Libras e o desenvolvimento local em contextos de territorialidades Campo Grande; UCDB, 2017.

STROBEL, Karin. História da educação de surdos. Florianópolis, 2009, Universidade Federal de Santa Catarina, Licenciatura em Letras-LIBRAS na modalidade a distância

MAZZOTA, Marcos J. S. Educação especial no Brasil: História e Política Públicas. São Paulo: Cortez, 1999

MERLEAU-PONTY, Maurice. O Visível e o Invisível. 4.ed. São Paulo: Perspectiva, 2009.

OLIVEIRA, Ruth dos S. B. de. Escola inclusiva: na teoria e/ou na prática. CIELLI, 2014.

ORLANDI, Eni Puccinelli. O discurso: Estrutura ou acontecimento. Campinas, Pontes, 1990.

Semântica e discurso: uma crítica à afirmação do óbvio. 2. ed. Campinas, São Paulo: Editora da Unicamp, 1995.

PÊCHEUX, Michel. Semântica e discurso. Uma crítica à afirmação do óbvio. 1975. Campinas: Unicamp, 1988.

SOUZA, Jessé. A invisibilidade da desigualdade brasileira. Belo Horizonte: Editora UFMG, 2006.

VERRI, Isabela. JORNAL SOCIOLÓGICO. A invisibilidade Social, 2009. Disponível em: http://jornalsociologico.blogspot.com/2009/05/invisibilidade-social.html acesso em 31.05.18

VILHALVA, Shirley. Despertar do silêncio. Rio de Janeiro. Editora Arara Azul, 2004. 